\title{
The impact of co-firing sunflower husk pellets with coal in a boiler on the chemical composition of flue gas
}

\author{
Monika Zajemska ${ }^{1, *}$, Paweł Urbańczyk ${ }^{2}$, Anna Poskart ${ }^{1}$, Dariusz Urbaniak $^{3}$, Henryk \\ Radomiak $^{1}$, Dorota Musiał ${ }^{1}$, Grzegorz Golański ${ }^{4}$ and Tomasz Wyleciał ${ }^{1}$ \\ ${ }^{1}$ Czestochowa University of Technology, Faculty of Production Engineering and Materials \\ Technology, Department of Industrial Furnaces and Environmental Protection, 19 Krajowej Av., \\ 42-201 Czestochowa, Poland \\ ${ }^{2}$ Office of Technical Inspection, 8 Przybylaka Str., 41- 300 Dąbrowa Górnicza, Poland \\ ${ }^{3}$ Czestochowa University of Technology, Institute of Thermal Machinery, 21 Krajowej Av., \\ 42-201 Czestochowa, Poland \\ ${ }^{4}$ Czestochowa University of Technology, Faculty of Production Engineering and Materials \\ Technology, Institute of Materials Engineering, 19 Krajowej Av., 42-201 Czestochowa, Poland
}

\begin{abstract}
The aim of the article is the offer of control of environmentally undesirable products of coal and biomass co-firing with the use of numerical methods. The article analyzes the impact of co-combustion of coal and pellets made of sunflower husk in power plant boiler with a capacity of 125 MW on the composition of the flue gas. Based on the data obtained from a real object, in particular: the combustion temperature, the reagent fluxes, i.e. air, coal and biomass, as well as the elemental composition of the fuels supplied into the boiler, the initial conditions were formulated and the computer simulations were made, leading to determining the chemical composition of flue gas. Numerical calculations were performed using the latest version of CHEMKIN-PRO software. Chemical mechanism was developed by the Italian group The CRECK Modeling and it included 134 compounds and 4169 chemical reactions, including reactions of forming chlorine compounds. Additionally, the impact of selected parameters, e.g. temperature on the chemical composition changes of the combustion products was analyzed. Developed calculation model with the implemented chemical mechanism was verified by data collected from the real conditions, leading to increasing the reliability of the results.

The calculations showed that the most important influence on the composition of the flue gas from the co-firing process of coal with sunflower husk has a composition of biomass. It should be emphasized that the results of computer simulations obtained by the authors have an useful aspect and can be applied in practice, especially to the analysis of the mechanism of chloride corrosion which is possible to occur due to the chlorine content in the biomass. They may also be useful for evaluating the unburned hydrocarbons produced by combustion of rich mixtures $(\lambda<1.0)$.
\end{abstract}

* Corresponding author: zajemska@wip.pcz.pl 


\section{Introduction}

Co-firing of biomass with coal can be considered at the moment for not only economical, but also an ecological way of its energy use. Noteworthy is the fact that the co-firing does not require costly modernization of existing energy systems. One of the most important factor is the appropriate share of biomass in the fuel mixture [1-4].

The biomass have the greatest practical importance in the power industry, where the combustion process, in spite of its complexity and the many difficulties both logistics (transport and storage of biomass) and technical (preparation of biomass to combustion, i.e. drying, grinding, supplying, etc.), is carried out on a large scale [1-3, 5]. Most of the problems with the energetic use of biomass is associated with the disadvantages of biomass (e.g. large and variable, depending on many factors, moisture content), and the considerable differences in physicochemical properties compared to coal [6-9]. This variety is especially present in the content of the element carbon (in the biomass it is almost two times less than in the coal) and element oxygen (about four times greater the content in the biomass), and the volatiles, as well as the moisture. The presence of chlorine, potassium, sodium and phosphorus is significant, because these elements can cause many operating problems during combustion process such as slagging, fouling and corrosion [9-13].

In the power engineering most commonly used is biomass from plants in the form of pellets. In the recent times the silvers, woodchips, sawdust, straw of cereal and rape as well as pellets made of sunflower husk are popular [14-17]. Their biggest advantages are the high caloric value of up to $21 \mathrm{MJ} / \mathrm{kg}$ and a relatively low chlorine content compared to other types of biomass $[10,14,15,18]$.

The process of biomass co-firing due to its diverse chemical composition has a significant impact on emissions of pollutants such as $\mathrm{SO}_{2}$ and $\mathrm{NO}_{\mathrm{x}}$, as well as the chlorine compounds (e.g. $\mathrm{HCl})[19,20]$. Therefore, it is extremely important to monitoring the chemical composition of flue gas during biomass combustion, in particular sulphur, chloride or potassium. Only the appropriate selection of the quantity and quality of biomass can contribute to the economical and ecological effects $[3,5,10]$.

The results of calculations, in particular the estimation of $\mathrm{HCl}$ content in the exhaust gas can be extremely useful in the real conditions, namely during the assessment of the risk of corrosion being a result of co-combustion of fuels containing chlorine in their composition. Furthermore, this results can be an important part of discussion on the modernization of existing combustion chambers, as well as these newly designed.

\section{The procedure of modeling}

Calculations of the chemical composition of the products of coal and biomass co-firing were made using the latest version of CHEMKIN-PRO software. The chemical mechanism was taken from the website [21] of The Creck Modeling Group. The extended chemical mechanism used in calculations is adapted for burning of solid fuels, in particular biomass. The reactions set includes reactions of formation of both the $\mathrm{NO}_{\mathrm{x}}$ and $\mathrm{SO}_{2}$, as well as the chlorine. It should be noted that the calculations with simplified mechanisms were also performed, but the results showed significant differences in the measured and calculated values of concentrations. Whereas the best agreement with experimental results was obtained for the mechanism proposed in this article. The chemical mechanism of combustion included 134 compounds and 4169 reactions. The Perfect Stirred Reactor (PSR) was used in the calculation model.

Initial conditions were based on data from a power (steam) boiler, OP-140, operating in one of the national heating plant, namely: 
- dimensions of the combustion chamber: a cross-section of the combustion chamber $6.055 \times 6.055 \mathrm{~m}$; height of the cuboid $21.75 \mathrm{~m}$;

- boiler power - 112.5 MW (in steam); $128 \mathrm{MW}$ (in fuel);

- the amount, power and type of built-up burners: 4 pcs. of dust burners, burner heat output of $32 \mathrm{MW}$;

- $\quad$ average flow of fuel, coal $-5.10 \mathrm{~kg} / \mathrm{s}$ biomass $-0.53 \mathrm{~kg} / \mathrm{s}$;

- average flow of air $-37.02 \mathrm{~m}^{3} / \mathrm{s}$;

- temperature of the preheated air $-246^{\circ} \mathrm{C}$;

- $\quad$ average temperature of the exhaust gas in the chamber - $1373 \mathrm{~K}$;

- $\quad$ excess air ratio $\lambda=1.47$;

- technical and elemental analysis of coal and biomass (Table 1);

- $\quad$ average flue gas composition: $\mathrm{O}_{2}=6.7 \% ; \mathrm{CO}_{2}=13 \% ; \mathrm{CO}=29 \mathrm{ppm} ; \mathrm{NO}=153$ ppm; $\mathrm{SO}_{2}=320 \mathrm{ppm} ; \mathrm{NO}_{\mathrm{x}}=161 \mathrm{ppm}$.

Table 1. Technical and elemental analysis of coal and pellets made of sunflower husk.

\begin{tabular}{|c|c|c|c|c|c|c|c|c|c|}
\hline Fuel & $\begin{array}{c}\mathbf{Q} \\
\mathrm{kJ} / \mathrm{kg}\end{array}$ & $\begin{array}{c}\mathbf{M} \\
\%\end{array}$ & $\begin{array}{c}\mathbf{A} \\
\%\end{array}$ & $\begin{array}{c}\mathbf{C} \\
\%\end{array}$ & $\begin{array}{c}\mathbf{N} \\
\%\end{array}$ & $\begin{array}{c}\mathbf{S} \\
\%\end{array}$ & $\begin{array}{c}\mathbf{H} \\
\%\end{array}$ & $\begin{array}{c}\mathbf{O} \\
\%\end{array}$ & $\begin{array}{c}\mathbf{C l} \\
\%\end{array}$ \\
\hline coal & 22361 & 12.10 & 17.64 & 55.60 & 0.90 & 0.46 & 3.50 & 9.80 & - \\
\hline pellet & 16466 & 13.60 & 5.30 & 44.07 & 1.15 & 0.18 & 5.332 & 30.36 & 0.078 \\
\hline
\end{tabular}

\section{The results of computer simulations}

As a result of the calculation the chemical composition of the flue gas at the outlet of boiler was obtained. Only selected compounds were examined, namely, $\mathrm{NO}, \mathrm{SO}_{2}, \mathrm{CO}_{2}, \mathrm{CO}, \mathrm{O}_{2}$ and $\mathrm{HCl}$. The calculated concentration values were compared with measured values (Fig. 1).

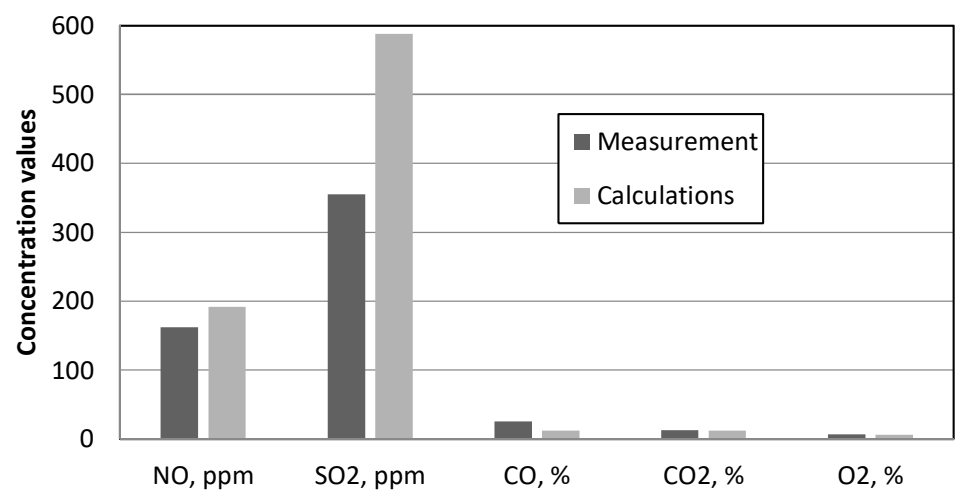

Fig. 1. Comparison of selected results of the calculated and measured values.

Fig. 1 shows that the calculated concentrations are in most cases close to the values obtained from real conditions. The biggest differences were observed for sulfur dioxide. The calculated concentration of sulfur dioxide in the flue gas was higher by about $200 \mathrm{ppm}$ from measured concentrations and reached a value of $588 \mathrm{ppm}$ and $355 \mathrm{ppm}$ respectively. Higher levels were also observed for nitric oxide, however not so large as in the case of $\mathrm{SO}_{2}$, namely the calculated concentration reached value of $192 \mathrm{ppm}$, and the measured was equal $162 \mathrm{ppm}$. Values of other concentrations, i.e. $\mathrm{CO}, \mathrm{O}_{2}$ and $\mathrm{CO}_{2}$ were comparable. 
Occurred discrepancies can be explained primarily by the fact that the elemental composition of biomass is quite varied, which depends on its suppliers (Table 2). Much higher concentrations of $\mathrm{SO}_{2}$ observed during calculations what is associated with the sulfur content in the pellet of sunflower husk. As is apparent from Table 2, the sulfur content in the biomass varies from 0.1 to $0.25 \%$. For the calculations a sulfur content equal to 0.18 was applied while in fact this value in a burned fuel could be much lower.

Table 2. Technical and elementary analysis of pellets made of sunflower husk, depending on the supplier.

\begin{tabular}{|l|c|c|c|}
\hline & Supplier 1 & Supplier 2 & Supplier 3 \\
\hline $\mathrm{W}, \%$ & 8.9 & 8.7 & 11.3 \\
\hline $\mathrm{A}, \%$ & 5.2 & 4.2 & 3.4 \\
\hline $\mathrm{V}, \%$ & 68.0 & 69.2 & 66.8 \\
\hline Q, MJ/kg d. m & 16.9 & 17.3 & 16.3 \\
\hline & \multicolumn{3}{|c|}{ Content of component, \% } \\
\hline $\mathrm{C}$ & 44.94 & 45.27 & 44.17 \\
\hline $\mathrm{H}$ & 5.37 & 5.52 & 5.21 \\
\hline $\mathrm{N}$ & 1.06 & 1.66 & 0.82 \\
\hline $\mathrm{S}$ & 0.17 & 0.253 & 0.09 \\
\hline $\mathrm{Cl}$ & 0.071 & 0.03 & 0.05 \\
\hline $\mathrm{F}$ & 0.023 & 0.01 & 0.02 \\
\hline $\mathrm{Na}$ & 0.021 & 0.01 & 0.01 \\
\hline $\mathrm{K}$ & 1.402 & 1.02 & 0.89 \\
\hline $\mathrm{O}$ & 34.31 & 34.35 & 34.96 \\
\hline
\end{tabular}

Due to the fact that the combustion process in the analyzed boiler occur in conditions of varying temperatures being in the range of 1300 to $1440 \mathrm{~K}$ additionally the effect of temperature on the chemical composition of selected combustion products was analyzed. As an example the mole fraction of $\mathrm{NO}, \mathrm{SO}_{2}$ and $\mathrm{HCl}$ were presented in the Figs. 2-4, respectively. 


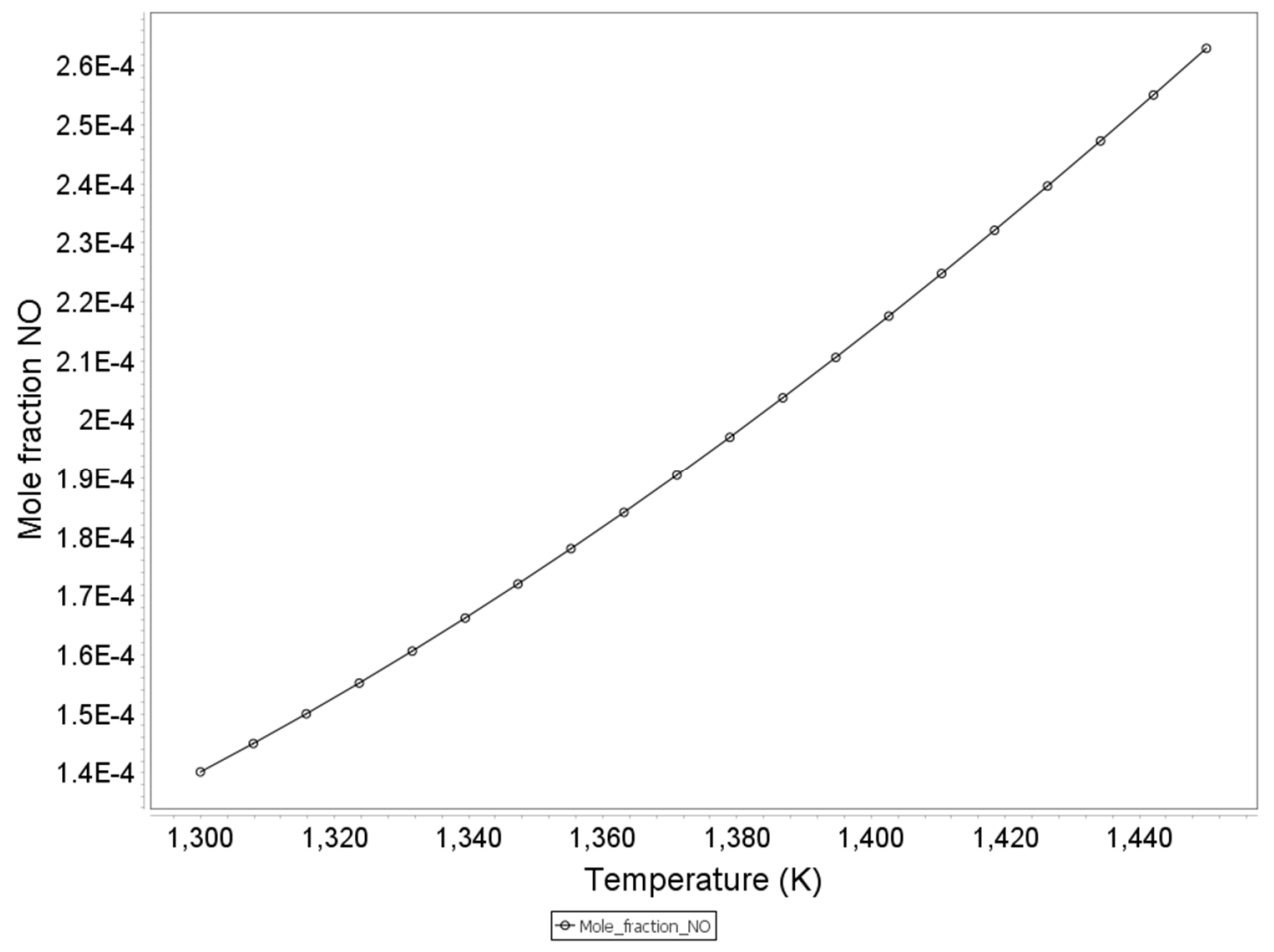

Fig. 2. The change of the molar fraction of $\mathrm{NO}$ as a function of the combustion temperature.

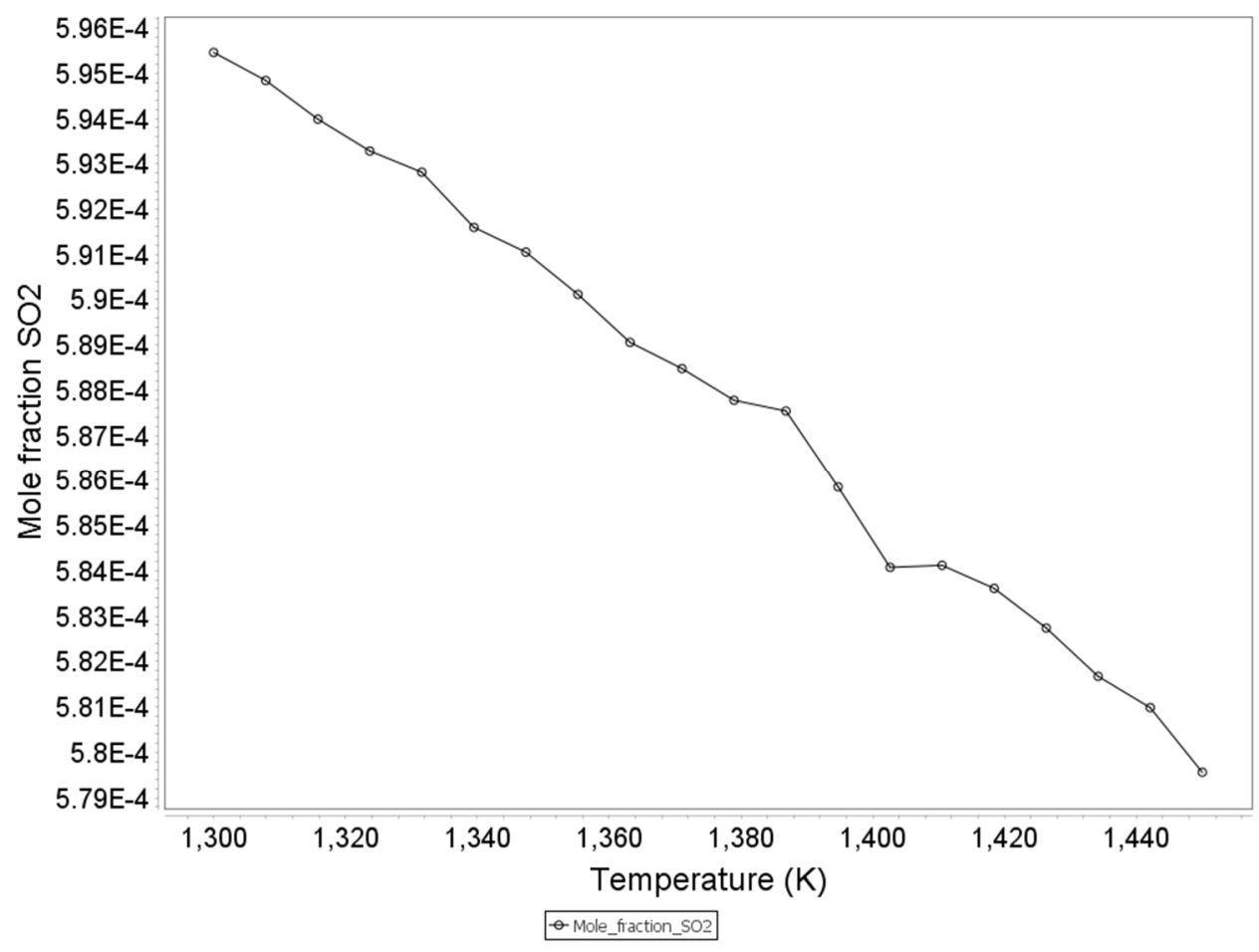

Fig. 3. The change of the molar fraction of $\mathrm{SO}_{2}$ as a function of combustion temperature. 


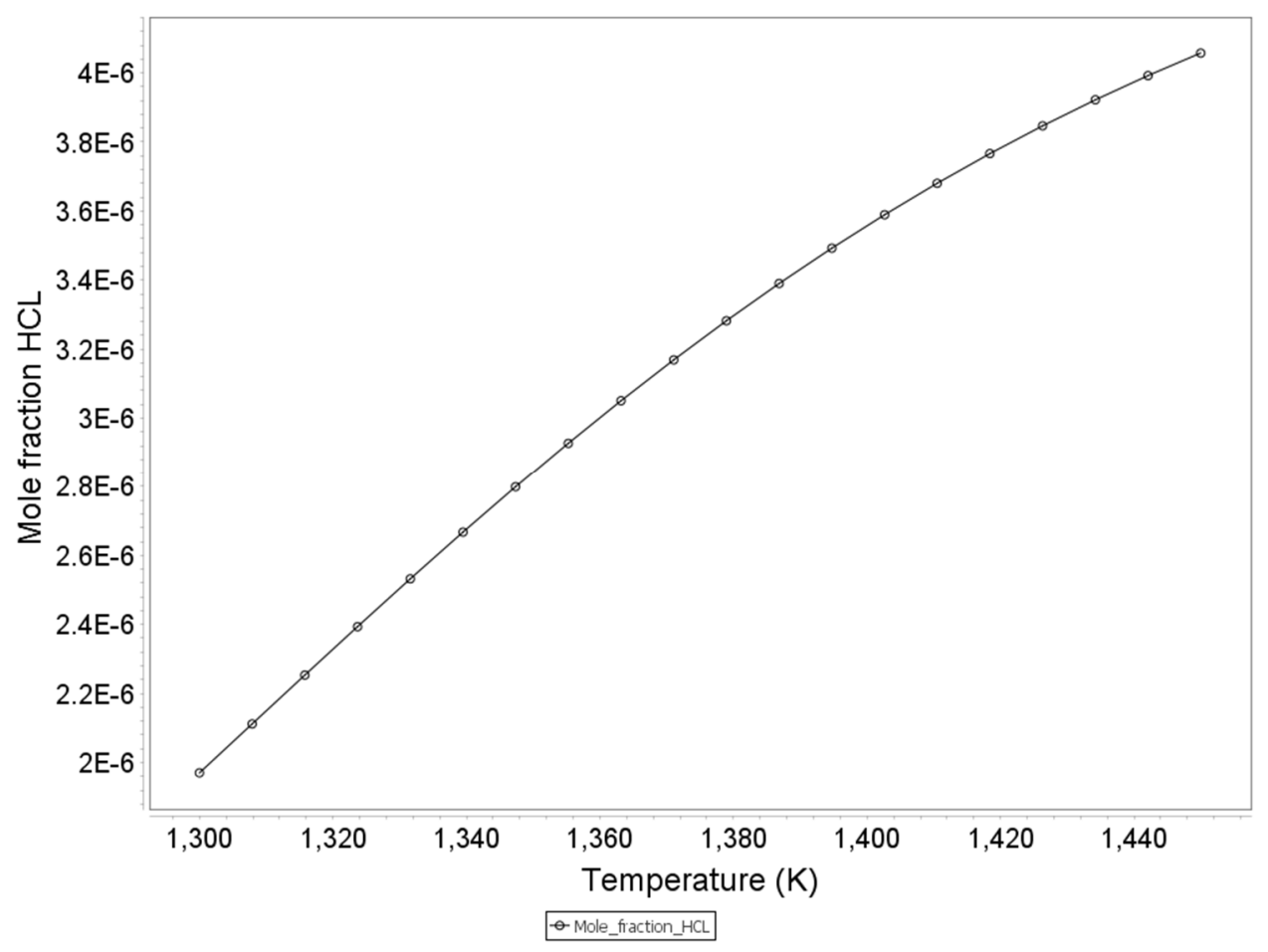

Fig. 4. The change of the molar fraction of $\mathrm{HCl}$ as a function of combustion temperature.

As can be seen from the Fig. 2-4 the effect of temperature is most noticeable in the case of NO. As shown in Fig. 2 the NO concentration increases with temperature and for the highest analyzed temperature, i.e. $1440 \mathrm{~K}$ it reaches a value of $260 \mathrm{ppm}$, while at a temperature of approx. $1300 \mathrm{~K}$ this value was slightly above $140 \mathrm{ppm}$. In the case of $\mathrm{SO}_{2}$ concentration (Fig. 3 ) no significant difference in the concentration values as a function of temperature was observed. For all the analyzed temperature range, these values vary from 579 to $596 \mathrm{ppm}$. The situation is similar in the case of $\mathrm{HCl}$ (Fig. 4). The change of temperature for studied range of temperature did not significantly affect on the change in concentration of $\mathrm{HCl}$. The concentration values are within the range between 2 to $4 \mathrm{ppm}$.

\section{Summary}

The calculations showed that a decisive influence on the composition of the flue gas from the co-firing process of coal with sunflower husk has a composition of biomass. Not without significance is also the combustion temperature, which significantly affects the concentration of nitrogen oxides in flue gas (Fig. 2).

The greatest differences in the calculated and measured concentrations was observed for sulfur dioxide in flue gases. The calculated values were by approx. $40 \%$ higher than the measured values. The reason for such a large discrepancy was an assumption in the calculations a relatively high sulfur content of the fuel in comparison to others (Table 2). The smallest differences were recorded for oxygen and carbon dioxide, which proves the correctness of the model adopted for the calculations, as well as the chemical mechanism. 
In order to avoid the chloride corrosion risk a particularly important was to evaluate the content of $\mathrm{HCl}$ in the flue gas. It has been shown that the temperature in the analyzed range i.e. 1300-1440 $\mathrm{K}$ does not significantly affect $\mathrm{HCl}$ formation.

It should be emphasized that $t$ he use of CHEMKIN-PRO software in the calculations can be very useful for the evaluation of biomass co-firing products at higher its content than analyzed in the article (10\% mass fraction, $7.5 \%$ share of the heat). Leading combustion of biomass with greater than $10 \%$ share in the mixture, due to the enhancement of such phenomenon as corrosion, special control is required.

In addition, due to the fact that the CHEMKIN-PRO software allows for the analysis of the chemical mechanisms of the formation of compounds responsible for the corrosion, it can be used at the stage of design of boilers, in particular in regard to the proper selection of construction materials.

\section{References}

1. A. Zyga, Wspótspalanie jako metoda konwersji biomasy. Materiały konferencyjne „Nowoczesna Energetyka Europy Środkowo-Wschodniej 2015”. http://kne.itc.pw.edu.pl/attachments/article/154/Agnieszka\%20Zyga.pdf

2. T. Golec, R. Lewtak, B. Świątkowski, B. Glot, Czysta Energia 9, 26-29 (2010)

3. K. Nowak, D. Proszak-Miąsik, S. Rabczak, JCEEA, 4, 147-154 (2014)

4. S. Tokarski, K. Głód, M. Sciążko, J. Zuwała, Energy 92, 24-32 (2015)

5. $\quad$ S. Grądziel, K. Majewski, Piece Przemysłowe \& Kotły V-VI, 37-43 (2013)

6. K. Han, S. Niu, CH. Lu, Process Saf. Environ. 88, 425-430 (2010)

7. B.M. Jenkins, L.L. Baxter, T.R. Miles, T.R. Miles, Combustion properties of biomass. Fuel Process. Technol. 54, 17-46 (1998)

8. R. Saidur, E.A. Abdelaziz, A. Demirbas, M.S. Hossain, S. Mekhilef, Renew. Sust. Energ. Rev. 15, 2262-2289 (2011)

9. J. Mółka, B. Łapczyńska - Kordon, Inżynieria rolnicza 6, 141-147 (2011)

10. N. Bątorek-Giesa, B. Jagustyn, Ochrona Środowiska i Zasobów Naturalnych 40, 396401 (2009)

11. E. Cardozo, C. Erlich, L. Alejo, H. Torsten, Fuel 115, 778-787 (2014)

12. A. Magdziarz, A.K. Dalai, J.A. Koziński, Fuel 6, 135-145 (2016)

13. G. Golański, J. Kępa, Nowoczesne stale dla energetyki - charakterystyka (Wydawnictwo Politechniki Częstochowskiej, Częstochowa, 2011)

14. V.K. Verma, S. Bram, F. Delattin, P. Laha, I. Vandendael, A. Hubin, J. De Ruyck, Appl. Energ. 90, 17-23 (2012)

15. R. Lopez, C. Fernandez, J. Fierro, J. Cara, O. Martínez, M.E. Sanchez, Energy 74, 845854 (2014)

16. A.A. Zabaniotou, E.K. Kantarelis, D.C. Theodoropoulos, Bioresource Technol. 99, 3174-3181 (2008)

17. K. Sirisomboon, P. Charernporn, J. Energy Inst. 30, 1-8 (2015)

18. S.V. Vassilev, D. Baxter, Ch.G. Vassileva, Fuel 117, 152-183 (2014)

19. A. Magdziarz, M. Wilk, M. Zajemska, Chem. Process Eng. 32, 423-433 (2011)

20. A. Magdziarz, M. Wilk, Rynek Energii 99, 127-130 (2012)

21. http://creckmodeling.chem.polimi.it/ 